\title{
Discurso del Sr. Carlos Saavedra Rubilar, Rector de la Universidad de Concepción
}

Estimadas y estimados asistentes,

$\mathrm{T}$ RAS HOJEAR EL TEXTO que hoy celebra su presentación en sociedad, surgió de entre sus páginas una pregunta que permaneció activa en mi mente al cerrar el libro: “¿Adónde hallaremos la expresión de nuestra sociedad, el espejo en que se refleja nuestra nacionalidad?” (Bradu, 2019, p. 29). La pregunta la hace José Victorino Lastarria, por ahí por 1842, pero se reiteró entre 1958 y 1962, como bien señala Fabienne Bradu, cuando el poeta y colega nuestro, don Gonzalo Rojas, organizó los Encuentros de Escritores en Concepción. La respuesta fue dada entre esos años por los destacados literatos y pensadores que atravesaron el Arco de Medicina de nuestra Universidad e instalaron allí sus pertrechos para elaborar ese espejo del que habla Lastarria, y darse cuenta de que las ataduras que hasta el momento los sujetaban habían sido quitadas, de modo que la identidad latinoamericana, y con ella, su literatura, no tenía nada que envidiar a la europea o norteamericana. América, extendida en sus infiernos, como reza el verso nerudiano de la Pinacoteca, comenzó a ser mirada no desde la altura, sino desde el horizonte.

El culpable de este despertar, el culpable de mostrarnos el paraíso fue el profesor Gonzalo Rojas. Contratado por el rector Enrique Molina para crear el Departamento de Castellano, en 1952, se encargó rápidamente de formar equipo con los profesores ya existentes y de contratar otros nuevos, algunos incluso de entre los mismos ayudantes. Así, los nombres de René Cánovas, Luis Muñoz, Juan Loveluck, Jaime Concha, Gastón von dem Busche, Romano Vallebuona, entre otros, llegaron a ser conocidos por muchas generaciones de pedagogos, quienes, ya egresados, ejercieron en los liceos de la ciudad penquista y en diversos lugares de nuestro país, difundiendo los conocimientos e ideas que estos preclaros académicos les legaron.

Sin embargo, no fue su rol al interior del Departamento de Castellano el que desencadenó el milagro, sino su gestión como Director de Extensión y Comunicaciones. En esta función, creó, en 1955 y a instancias de 
don David Stitchkin, las Escuelas de Temporada -hoy, Escuela de Veranocumpliendo así una de las aspiraciones fundacionales de la Universidad de Concepción: democratizar el conocimiento, de modo que todo aquel que quisiera ampliar su intelecto en la Universidad, pudiera hacerlo durante el mes de enero de cada año. Hasta hoy, verano tras verano la comunidad local tiene acceso a una nutrida oferta académica y cultural que le permite acercarse al conocimiento surgido en nuestra Universidad y a disfrutar de espectáculos de gran calidad artística, que les permiten desarrollar libremente su espíritu.

Dentro de esta función como gestor cultural, Gonzalo Rojas tuvo la genialidad de organizar los míticos Encuentros de Escritores de Chile y América, realizados en la Universidad de Concepción entre 1958 y 1962. En palabras del rector Stitchkin, para Concepción "era indispensable crear contactos de esta naturaleza. No me conformaría nunca con que Concepción continuara siendo una isla culturalmente hablando si estuviera en la mano de su Universidad el evitarlo" (como se cita en Bradu, 2019, pp. 3435). Los encuentros organizados por el poeta lograron poner a Concepción y a su Universidad en los ojos del mundo. Gonzalo Rojas, sin más que con su "confianza y cabeza dura", desde el seno universitario penquista, quiso -y lo logró- "cambiar la aldea”. ¿De qué otra manera podríamos estar reunidos hoy, casi 60 años más tarde, estudiando los luminosos impactos de su atrevimiento?

Los encuentros nacionales e internacionales muestran la ambición, la audacia y la visión que guiaron al poeta para poder organizarlos y entender su alcance. Estos encuentros, dice Rojas, constituyen un método de investigación que consiste en la averiguación polémica de las ideas culturales y literarias de América Latina, en oposición al acostumbrado sistema del académico enclaustrado (en la aldea) y desconectado del mundo. No seré yo, sino los especialistas, quienes hablen de él en su dimensión de poeta. Como sabemos, estamos frente a una figura importante de las letras en Iberoamérica, que ha tenido los más altos reconocimientos a nivel mundial. No por nada se le reconoce como "el poeta mayor".

Como Casa de Estudios a la que perteneció, queremos rendirle nuevamente un homenaje al profesor Gonzalo Rojas Pizarro, como continuación del que, en 2011, el Departamento de Español realizara de forma póstuma, a propósito de su fallecimiento. Hoy queremos expresar a su familia, en especial a sus hijos, Rodrigo y Gonzalo, nuestra admiración y reconocimiento a la importante obra de su padre en la Universidad de Concepción. 
A Fabienne Bradu, investigadora que conoce más que nadie la figura del poeta y la historia de las ideas que circularon por la Universidad de Concepción de los tiempos de Gonzalo Rojas, vayan también nuestros agradecimientos y felicitaciones por este excelente libro, que nos honra como institución y que no nos cabe duda de que será lectura obligada para todo aquel que quiera conocer cómo, desde la provincia, un lebulense cambió la aldea.

Finalmente, agradecemos a Rafael López Giral, Gerente del Fondo de Cultura Económica en Chile, por su excelente disposición para compartir con nuestra Universidad de Concepción la publicación de esta obra.

\section{Muchas gracias.}

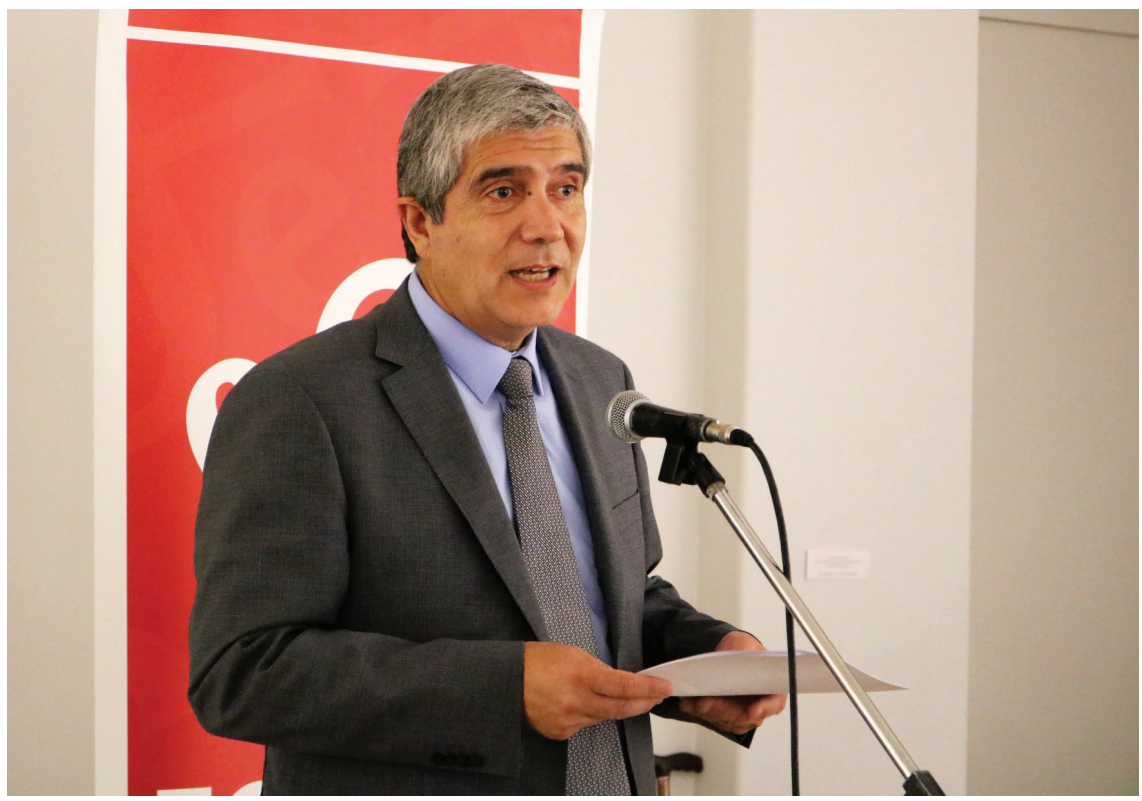

Dr. Carlos Saavedra Rubilar, Rector Universidad de Concepción. Concepción, 18 de enero de 2020. 